\title{
Framingham Heart Study I00K Project: genome-wide associations for blood pressure and arterial stiffness
}

\author{
Daniel Levy*1,2,3, Martin G Larson ${ }^{1,4}$, Emelia J Benjamin 1,3,5, \\ Christopher Newton-Cheh ${ }^{1,6}$, Thomas J Wang ${ }^{1,6}$, Shih-Jen Hwang ${ }^{1,2}$, \\ Ramachandran S Vasan ${ }^{1,3,5}$ and Gary F Mitchell ${ }^{1,7}$
}

\begin{abstract}
Address: 1The National Heart, Lung, and Blood Institute's Framingham Heart Study, Framingham, MA, USA, ${ }^{2}$ The National Heart, Lung, and Blood Institute, Bethesda, MD, USA, ${ }^{3}$ Boston University School of Medicine, Boston MA, USA, ${ }^{4}$ Department of Mathematics, Boston University, Boston, MA, USA, ${ }^{5}$ Division of Cardiology, Boston Medical Center, Boston, MA, USA, ${ }^{6}$ Division of Cardiology, Massachusetts General Hospital and Harvard Medical School, Boston, MA, USA and ${ }^{7}$ Cardiovascular Engineering Inc., Waltham, MA, USA

Email: Daniel Levy* - Levyd@nih.gov; Martin G Larson - mlarson@bu.edu; Emelia J Benjamin - emelia@bu.edu; Christopher NewtonCheh - cnewtoncheh@partners.org; Thomas JWang - tjwang@partners.org; Shih-Jen Hwang - hwangs2@nhlbi.nih.gov; Ramachandran S Vasan - vasan@bu.edu; Gary F Mitchell - garyfmitchell@mindspring.com

* Corresponding author
\end{abstract}

Published: 19 September 2007

BMC Medical Genetics 2007, 8(Suppl I):S3 doi:10.1 186/I47I-2350-8-SI-S3

This article is available from: http://www.biomedcentral.com/I47I-2350/8/SI/S3

(c) 2007 Levy et al; licensee BioMed Central Ltd.

This is an open access article distributed under the terms of the Creative Commons Attribution License (http://creativecommons.org/licenses/by/2.0), which permits unrestricted use, distribution, and reproduction in any medium, provided the original work is properly cited.

\begin{abstract}
Background: About one quarter of adults are hypertensive and high blood pressure carries increased risk for heart disease, stroke, kidney disease and death. Increased arterial stiffness is a key factor in the pathogenesis of systolic hypertension and cardiovascular disease. Substantial heritability of blood-pressure (BP) and arterial-stiffness suggests important genetic contributions.
\end{abstract}

Methods: In Framingham Heart Study families, we analyzed genome-wide SNP (Affymetrix I00K GeneChip) associations with systolic (SBP) and diastolic (DBP) BP at a single examination in 197I-1975 $(n=1260)$, at a recent examination in 1998-200I $(n=1233)$, and long-term averaged SBP and DBP from 197|-200I $(n=1327$, mean age 52 years, 54\% women) and with arterial stiffness measured by arterial tonometry (carotid-femoral and carotid-brachial pulse wave velocity, forward and reflected pressure wave amplitude, and mean arterial pressure; 1998-200I, $n=644$ ). In primary analyses we used generalized estimating equations in models for an additive genetic effect to test associations between SNPs and phenotypes of interest using multivariable-adjusted residuals. A total of 70,987 autosomal SNPs with minor allele frequency $\geq 0.10$, genotype call rate $\geq 0.80$, and Hardy-Weinberg equilibrium $p \geq 0.00$ I were analyzed. We also tested for association of 69 SNPs in six renin-angiotensin-aldosterone pathway genes with BP and arterial stiffness phenotypes as part of a candidate gene search.

Results: In the primary analyses, none of the associations attained genome-wide significance. For the six BP phenotypes, seven SNPs yielded $p$ values $<10^{-5}$. The lowest $p$-values for SBP and DBP respectively were rs $10493340(p=1.7 \times$ $\left.10^{-6}\right)$ and $r s 1963982\left(p=3.3 \times 10^{-6}\right)$. For the five tonometry phenotypes, five SNPs had $p$ values $<10^{-5}$; lowest $p$-values were for reflected wave $\left(r s 6063312, p=2.1 \times 10^{-6}\right)$ and carotid-brachial pulse wave velocity $\left(r s 770189, p=2.5 \times 10^{-6}\right)$ in MEF2C, a regulator of cardiac morphogenesis. We found only weak association of SNPs in the renin-angiotensinaldosterone pathway with BP or arterial stiffness.

Conclusion: These results of genome-wide association testing for blood pressure and arterial stiffness phenotypes in an unselected community-based sample of adults may aid in the identification of the genetic basis of hypertension and 
arterial disease, help identify high risk individuals, and guide novel therapies for hypertension. Additional studies are needed to replicate any associations identified in these analyses.

\section{Background}

Hypertension affects about one quarter of adults in industrialized countries [1] and carries a substantial burden of risk for cardiovascular disease (CVD), kidney disease, and death [2]. Increased arterial stiffness is a key factor in the pathogenesis of hypertension in older people and it contributes to the development of hypertensive target organ damage, CVD, and death [3-5]. Substantial heritability of blood pressure [6] and arterial stiffness [7]), as measured by arterial tonometry, points to genetic contributions to these cardiovascular phenotypes.

The search for genetic variants contributing to hypertension and arterial stiffness has focused on complementary approaches: linkage applied to rare Mendelian blood pressure disorders and to large family-based studies to identify positional candidate genes, and the study of biologically plausible candidate genes selected by virtue of their role in blood pressure regulation or vascular properties. A great deal is known about mutations responsible for Mendelian blood pressure disorders [8], but neither these rare variants nor more common variants in these genes account for substantial blood pressure variation in the general population. Similarly, although numerous linkage [9] and candidate gene association studies [10] have been conducted, there is a paucity of evidence that common genetic variation contributes to alterations in blood pressure or arterial stiffness in the general population.

Genome-wide association offers the opportunity to conduct analysis of common genetic variants unconstrained by prior knowledge of biological pathways in relation to phenotypes of interest. This approach succeeded in identifying the association of complement factor $\mathrm{H}$ with agerelated macular degeneration [11]. The Framingham Heart Study, which enrolled participants without regard to phenotype status, provides a setting for a genome-wide association study in a community-based sample in which selection bias is inherently low. In addition, because of the familial structure of the study, it also provides an opportunity to use genome-wide SNP data for family based association testing (FBAT) and linkage analyses.

In this report we provide results of a genome-wide association study of blood pressure and arterial stiffness, including results of generalized estimating equation (GEE) association testing, FBAT, and linkage, as well as a summary of associations of these phenotypes with candidate genes in the renin-angiotensin-aldosterone pathways.

\section{Methods \\ Study sample}

The Framingham Heart Study began in 1948 when 5209 men and women from Framingham, Mass, who were between 28 and 62 years of age were recruited to participate in an observational study [12]. Subjects underwent a medical history, physician-administered physical examination including blood pressure measurement, laboratory tests, and electrocardiography. Examinations have been repeated every 2 years. In 1971, 5124 offspring and spouses of offspring of original participants were recruited into the Framingham Offspring Cohort [13]. The offspring cohort was reexamined approximately every 4 years, except for an 8 year interval between their initial and second visit. All subjects gave written informed consent before each clinic visit, and the examination protocol was approved by the Institutional Review Board at Boston Medical Center (Boston, Mass).

\section{Blood pressure phenotypes}

At each clinic visit, the examining physician measured the systolic and diastolic BP in the left arm using a mercury column sphygmomanometer. BP was measured twice at each visit, with the exception of the first Offspring Cohort clinic visit, when it was measured once in about half the participants. Systolic and diastolic pressures were determined by the first and fifth Korotkoff sounds, respectively, and the two BP measurements were averaged to derive the systolic and diastolic pressures for that examination.

Examination cycles for the two cohorts were overlaid temporally as follows [offspring cohort/original cohort (earliest - latest year)]: examination 1/examination 12 (19711975), examination 2/examination 16 (1979-1983), examination 3/examination 18 (1983-1987), examination 4/examination 20 (1986-1991), examination 5/ examination 22 (1990-1995), examination 6/examination 24 (1995-1998) and examination 7/examination 26 (1998-2001). Referring to offspring cycle numbers, the six BP phenotypes analyzed for this investigation were residuals for SBP and DBP at Examination 1, at Examination 7, and average of residuals from available Examinations 1 to 7. BP was imputed for treated observations as previously described [6]. No adjustment was made for untreated observations, which constituted the vast majority of BP values. Systolic and diastolic BP phenotypes were analyzed independently. Residuals were obtained from cohort- and examination-specific regression models accounting for sex, age and BMI; for DBP, age-squared was added. For inclusion in long-term BP analyses, each par- 
ticipant had to have BP measured on at least three examinations over a period of 12 years or more.

\section{Arterial stiffness phenotypes}

Arterial tonometry for assessment of arterial stiffness was conducted on Offspring Cohort participants attending their 7 th clinic examination. Five primary tonometry phenotypes were analyzed: carotid-femoral and carotid-brachial pulse wave velocity, forward and reflected pressure wave amplitude, and mean arterial pressure. Tonometry was performed in the supine position after 5 minutes of rest. Arterial tonometry with simultaneous ECG recording was obtained from brachial, radial, femoral and carotid arteries using a commercially available tonometer (SPT301, Millar Instruments, Houston, TX). Carotid-brachial, carotid-radial and carotid-femoral PWV were calculated as previously described [14]. Mean arterial pressure was calculated from the planimetered brachial arterial tracing after calibration to the brachial blood pressure, which was obtained by an oscillometric device. Forward pressure wave amplitude was defined as the difference between pressure at the waveform foot and pressure at the first systolic inflection point or peak of the carotid pressure waveform; reflected pressure wave amplitude was defined as the difference between the central systolic pressure and the pressure at the forward wave peak. Sex-specific regressions were conducted for each tonometry phenotype with the following covariates: age, age ${ }^{2}$, height, weight, to generate sex-specific residuals.

\section{Genotyping methods}

Details of the genotyping methods are available in the Executive Summary [15]. Briefly, 112990 autosomal SNPs on the Affymetrix $100 \mathrm{~K}$ chip were genotyped in the Boston University School of Medicine Genetics Laboratory on the Framingham Heart Study family plate set. SNPs were excluded for the following reasons: minor allele frequency $<10 \%(\mathrm{n}=38062)$; call rate $<80 \%(\mathrm{n}=2346)$; Hardy Weinberg equilibrium $\mathrm{p}$ value $<0.001(\mathrm{n}=1595)$, leaving 70,987 SNPs available for analysis.

\section{Statistical methods}

Standardized multivariable-adjusted blood pressure and tonometry residuals were generated as described above. Table 1 lists the covariates used for each phenotype. As described in the Executive Summary [15], we conducted association testing using family based association testing (FBAT), and generalized estimating equations (GEE) applied to the additive genetic effects model. In secondary analyses that used the GEE general genetic effects model, which is more sensitive to recessive genetic effects, to be more conservative, we limited analyses to two phenotypes: long-term SBP and long-term DBP, and we limited eligible SNPs to those with a minor allele frequency $>=$ 0.20 and Hardy-Weinberg equilibrium p value $>=0.05$.
The software package Merlin [16] was used to compute exact identity by descent linkage probabilities for allele sharing, and linkage analysis by variance component method was carried out SOLAR using 11,200 SNPs and STRs. Heritability was estimated using variance-components methods (SOLAR). For BP, 2155 study participants were used for examination 1 SBP and DBP, 1479 for examination 7, and 2009 for long-term average; 770 individuals were used in heritability analysis of arterial stiffness phenotypes.

\section{Candidate gene analyses}

GEE and FBAT additive genetic effect models were run for SNPs in or near 6 genes in the renin-angiotensin-aldosterone pathways. These genes were selected a priori because of a substantial body of literature implicating them in hypertension and altered vascular properties. All SNPs from $200 \mathrm{~Kb}$ proximal to the start and extending to $200 \mathrm{~kb}$ of the terminus of each gene were included in analysis providing the minor allele frequency was $>=0.1$, the genotype call rate was 0.8 , and the Hardy-Weinberg equilibrium $\mathrm{p}$ value was $>=0.001$.

\section{Results}

The six primary BP phenotypes were examination 1 SBP and DBP $(\mathrm{n}=1260)$, examination 7 SBP and DBP $(\mathrm{n}=$ $1233)$, and long-term averaged SBP and DBP $(\mathrm{n}=1327)$. The five primary arterial stiffness phenotypes were carotid-femoral and carotid-brachial pulse wave velocity, forward and reflected pressure wave amplitude, and mean arterial pressure $(n=644)$. The study sample available for BP phenotypes included up to 1327 individuals (mean age 52 years, $54 \%$ women for the long-term SBP and DBP phenotypes). The complete list of blood pressure and arterial stiffness phenotypes analyzed and the covariates used in generating sex-specific standardized residuals for each phenotype are listed in Table 1. Full disclosure of all GEE and FBAT associations for the traits listed in Table 1 can be found at the National Center for Biotechnology Information dbGaP website: http://web.ncbi.nlm.nih.gov/ projects/gap/framingham/cgi-bin/

study.cgi?id=phs000007.

Results of primary GEE models for an additive genetic effect for DBP, SBP, and arterial stiffness phenotypes are presented in Table 2a. None of the association results attained genome-wide significance. The lowest $\mathrm{p}$ values for DBP, SBP, and arterial stiffness phenotypes, respectively, were rs1963982 $\left(\mathrm{p}=3.31 \times 10^{-6}\right)$, rs $10493340(\mathrm{p}=$ $\left.1.7 \times 10^{-6}\right)$, and rs6063312 ( $\mathrm{p}=2.1 \times 10^{-6}$ for reflected wave amplitude). For the same three phenotype groups the number of associations with p values $<10^{-5}$ were 6,1 , and 5 , respectively. 
Table I: Phenotype List

\begin{tabular}{|c|c|c|c|c|c|}
\hline & & & Exam cycle/s & & \\
\hline & $\mathrm{N}^{*}$ & Offspring & Cohort & Adjustment & Covariates \\
\hline \multicolumn{6}{|c|}{ Primary Phenotypes } \\
\hline \multicolumn{6}{|c|}{ Blood Pressure } \\
\hline SBP I & 2 & 1 & 12 & Age and sex, multivariable & Cohort, sex, age, BMI \\
\hline SBP 7 & 2 & 7 & 26 & Age and sex, multivariable & Cohort, sex, age, BMI \\
\hline SBP I-7 & 2 & Mean of exams I-7 & Mean of exams $12,16,18,20,22,24,26$ & Age and sex, multivariable & Cohort, sex, age, BMI \\
\hline DBP I & 2 & 1 & 12 & Age and sex, multivariable & Cohort, sex, age, BMI \\
\hline DBP 7 & 2 & 7 & 26 & Age and sex, multivariable & Cohort, sex, age, BMI \\
\hline DBP I-7 & 2 & Mean of exams I-7 & Mean of exams 12, 16, 18, 20, 22, 24, 26 & Age and sex, multivariable & Cohort, sex, age, BMI \\
\hline \multicolumn{6}{|c|}{ Tonometry } \\
\hline Carotid-femoral PWV & 2 & 7 & Not included & Age and sex, multivariable & Sex, age, age ${ }^{\wedge} 2$, height, weight \\
\hline Carotid-brachial PWV & 2 & 7 & Not included & Age and sex, multivariable & Sex, age, age ${ }^{\wedge} 2$, height, weight \\
\hline Forward pressure wave & 2 & 7 & Not included & Age and sex, multivariable & Sex, age, age ${ }^{\wedge} 2$, height, weight \\
\hline Reflected pressure wave & 2 & 7 & Not included & Age and sex, multivariable & Sex, age, age ${ }^{\wedge} 2$, height, weight \\
\hline Mean arterial pressure & 2 & 7 & Not included & Age and sex, multivariable & Sex, age, age ${ }^{\wedge} 2$, height, weight \\
\hline
\end{tabular}

Secondary Phenotypes^

Blood Pressure

\begin{tabular}{|c|c|c|c|c|c|}
\hline DBP 2 & 2 & 2 & 16 & Age and sex, multivariable & Cohort, sex, age, BMI \\
\hline DBP 3 & 2 & 3 & 18 & Age and sex, multivariable & Cohort, sex, age, BMI \\
\hline DBP 4 & 2 & 4 & 20 & Age and sex, multivariable & Cohort, sex, age, BMI \\
\hline DBP 5 & 2 & 5 & 22 & Age and sex, multivariable & Cohort, sex, age, BMI \\
\hline DBP 6 & 2 & 6 & 24 & Age and sex, multivariable & Cohort, sex, age, BMI \\
\hline SBP 2 & 2 & 2 & 16 & Age and sex, multivariable & Cohort, sex, age, BMI \\
\hline SBP 3 & 2 & 3 & 18 & Age and sex, multivariable & Cohort, sex, age, BMI \\
\hline SBP4 & 2 & 4 & 20 & Age and sex, multivariable & Cohort, sex, age, BMI \\
\hline SBP 5 & 2 & 5 & 22 & Age and sex, multivariable & Cohort, sex, age, BMI \\
\hline SBP 6 & 2 & 6 & 24 & Age and sex, multivariable & Cohort, sex, age, BMI \\
\hline PP I & 2 & 1 & 12 & Age and sex, multivariable & Cohort, sex, age, BMI \\
\hline PP 2 & 2 & 2 & 16 & Age and sex, multivariable & Cohort, sex, age, BMI \\
\hline PP 3 & 2 & 3 & 18 & Age and sex, multivariable & Cohort, sex, age, BMI \\
\hline PP 4 & 2 & 4 & 20 & Age and sex, multivariable & Cohort, sex, age, BMI \\
\hline PP 5 & 2 & 5 & 22 & Age and sex, multivariable & Cohort, sex, age, BMI \\
\hline PP 6 & 2 & 6 & 24 & Age and sex, multivariable & Cohort, sex, age, BMI \\
\hline PP 7 & 2 & 7 & 26 & Age and sex, multivariable & Cohort, sex, age, BMI \\
\hline PP I-7 & 2 & Mean of exams I-7 & Mean of exams $12,16,18,20,22,24,26$ & Age and sex, multivariable & Cohort, sex, age, BMI \\
\hline \multicolumn{6}{|c|}{ Tonometry } \\
\hline I/CF-PWV & 2 & 7 & Not included & Age and sex, multivariable & Sex, age, age ${ }^{\wedge} 2$, height, weight \\
\hline $\mathrm{Al}$ & 2 & 7 & Not included & Age and sex, multivariable & Sex, age, age ${ }^{\wedge} 2$, height, weight \\
\hline CPP & 2 & 7 & Not included & Age and sex, multivariable & Sex, age, age ${ }^{\wedge} 2$, height, weight \\
\hline CR-PWV & 2 & 7 & Not included & Age and sex, multivariable & Sex, age, age ${ }^{\wedge} 2$, height, weight \\
\hline DBP-osc & 2 & 7 & Not included & Age and sex, multivariable & Sex, age, age ${ }^{\wedge} 2$, height, weight \\
\hline PA-I & 2 & 7 & Not included & Age and sex, multivariable & Sex, age, age ${ }^{\wedge} 2$, height, weight \\
\hline PA-2 & 2 & 7 & Not included & Age and sex, multivariable & Sex, age, age ${ }^{\wedge} 2$, height, weight \\
\hline PP-osc & 2 & 7 & Not included & Age and sex, multivariable & Sex, age, age ${ }^{\wedge} 2$, height, weight \\
\hline RWTT & 2 & 7 & Not included & Age and sex, multivariable & Sex, age, age ${ }^{\wedge} 2$, height, weight \\
\hline SBP-osc & 2 & 7 & Not included & Age and sex, multivariable & Sex, age, age ${ }^{\wedge} 2$, height, weight \\
\hline
\end{tabular}

$*_{\mathrm{n}}=$ number of phenotypes analyzed

^Association results for primary and secondary phenotypes are available on the worldwide web at: http://web.ncbi.nlm.nih.gov/projects/gap/ framingham/cgi-bin/study.cgi?id=phs000007

$\mathrm{Al}=$ augmentation index; $\mathrm{CPP}=$ central pulse pressure; $\mathrm{CB}-\mathrm{PWV}=$ carotid brachial pulse wave velocity; $\mathrm{CF}-\mathrm{PWV}=$ carotid-femoral pulse wave velocity; $C R-P W V=$ carotid-radial pulse wave velocity; $\mathrm{DBP}=$ diastolic blood pressure; $\mathrm{DBP}-\mathrm{osc}=$ brachial $\mathrm{DBP}$ by oscillometric device; $\mathrm{FW}=$ forward wave amplitude; MAP = mean arterial pressure; PA-I = apparent peripheral amplification; PA-2 = true peripheral amplification; PP = pulse pressure; $\mathrm{PP}$-osc = brachial $\mathrm{PP}$ by oscillometric device; $\mathrm{RW}=$ reflected wave amplitude; $\mathrm{RWTT}=$ reflected wave transit time; $\mathrm{SBP}=$ systolic blood pressure; SBP-osc = brachial SBP by oscillometric device; I/CF-PWV = inverse of CF-PWV. 
FBAT models for an additive genetic effect are presented in Table 2b. Two SNPs for DBP and one for SBP yielded $\mathrm{p}$ values $<10^{-5}$. Of note, rs10520569 in ADAMTSL3 was associated with DBP $\left(4.2 \times 10^{-5}\right)$ and SBP $\left(1.4 \times 10^{-4}\right)$. For arterial stiffness phenotypes there were $2 \mathrm{p}$ values $<10^{-5}$, including rs792833 in COL8A1.

Linkage analyses (Table 2c) yielded a LOD score of 3 for long-term SBP on chromosome 15 at $100 \mathrm{Mb}$. Several tonometry linkage peaks exceeded a LOD score of 3, including a LOD of 5.0 for reflected wave (chromosome 8 at $19 \mathrm{Mb}$ ). Heritability estimates (Table 2d) were high for long-term average DBP $\left(\mathrm{h}^{2}=0.55\right)$ and SBP $\left(\mathrm{h}^{2}=0.57\right)$, and intermediate for the other BP phenotypes $\left(\mathrm{h}^{2}=0.28-\right.$ $0.45)$. Among the arterial stiffness phenotypes, heritability was high for the reflected arterial waveform $\left(h^{2}=0.66\right)$, low for carotid-brachial PWV $\left(\mathrm{h}^{2}=0.02\right)$, and intermediate for the other phenotypes $\left(\mathrm{h}^{2}=0.22-0.43\right)$. These heritability results are consistent with our prior findings $[6,7]$.

Secondary analyses using the GEE general genetic effects model ( 2 degrees of freedom; more sensitive in detecting recessive effects) are presented in Table 3 . The lowest $\mathrm{p}$ value for long-term DBP was in CCL20 (rs7591163, p = $\left.2.3 \times 10^{-7}\right)$ and for SBP was in CDH13 (rs3096277, $\mathrm{p}=9.9$ $\left.\times 10^{-8}\right)$. Of note, SNPs in CDH13, CCL20, and WDR69 were associated with DBP and SBP. GEE general effects models for the tonometry phenotypes identified association of mean arterial pressure with TGFBR2 (rs3773643, p $\left.=2 \times 10^{-7}\right)$.

Geometric means of GEE association results (additive genetic effect model) for SBP and DBP considered jointly are summarized in Table 4. The lowest $\mathrm{p}$ values were noted for Examination $1 \mathrm{BP}$ values (rs10493340, $\mathrm{p}=1.5$ $\times 10^{-5}$ ). Geometric means of association results for the 5 tonometry phenotypes considered concurrently yielded

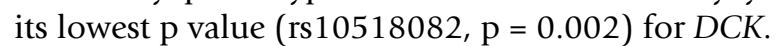

SNPs in 6 renin-angiotensin-aldosterone pathway genes were analyzed for association with the BP and tonometry phenotypes (Table 5). A total of 69 SNPs qualified for analysis (minor allele frequency $>=0.1$, Hardy Weinberg equilibrium $\mathrm{p}>=0.001$, call rate $>=0.8$ ). For the primary traits there were few associations from GEE models for an additive genetic effect with $\mathrm{p}$ values $<0.05$ and none with $\mathrm{p}<0.001$.

\section{Discussion and conclusion}

We provide results of genome-wide association study for 6 blood pressure and 5 arterial stiffness phenotypes in a carefully characterized study sample. Association analyses and linkage reveal a number of intriguing results. For the GEE model of additive genetic effects (Table 2a) there were 7 SNPs with p values $<10^{-5}$ for blood pressure and 5 for arterial stiffness phenotypes. Among the GEE additive effect model results the most likely candidate genes were MEF2C, SYNE1, and TNFSF11, which were associated with arterial stiffness. We have not yet attempted replication of our results. Follow-up genotyping of the top SBP and DBP SNPs reported in our study sample in additional Framingham participants is planned; additional replication attempts will be needed in independent samples to confirm any of the association results we report.

FBAT (Table 2b) identified association of COL8A1 with arterial stiffness ( $\mathrm{p}$ value $6 \times 10^{-6}$ for rs792833). This gene codes for type VIII collagen, which is produced by aortic endothelial cells [17], suggesting a biologically plausible association.

Linkage yielded a LOD score of 3, approaching genomewide significance, for long-term SBP on chromosome 15. A meta-analysis of blood pressure and hypertension linkage studies did not identify this as a region of interest [9]. The lower LOD scores for long-term SBP on chromosome 17 ( $67 \mathrm{cM})$ in this investigation compared with our prior findings [6] appears to be largely due to differences in phenotype definition of long-term SBP with the exclusion of early examination BP values in the original cohort participants and the inclusion of offspring cohort examination 7 blood pressures in this analysis. When linkage analyses were repeated with the inclusion of the early original cohort exams using the prior phenotype definitions, the same linkage peak on chromosome 17 emerged (LOD $>4$ ).

For tonometry phenotypes, we found LOD scores for reflected wave amplitude of 5.0 (chromosome 8 at 19 $\mathrm{Mb}$ ) and 3.2 (chromosome 4, $169 \mathrm{Mb}$ ) near peaks for this phenotype that we previously reported in a largely overlapping study sample [7]. Similarly, we once again identified a linkage peak for carotid-femoral pulse wave velocity (LOD 3.0; chromosome 2 at $74 \mathrm{mb}$ ).

Compared with the primary GEE model for additive genetic effects (Table 2a), a different set of SNPs was identified in secondary GEE general effects models (Table 3) for long-term DBP and SBP, including 2 SNPs with p values $<10^{-6}$. Differences in model results may be due to the greater sensitivity of the general model to detect recessive genotype effects. SNPs in CCL20, CDH13, and LPP were associated with both long-term SBP and DBP. GEE general genetic effects models for arterial stiffness phenotypes yielded the lowest $\mathrm{p}$ value $\left(\mathrm{p}=1.99 \times 10^{-7}\right)$ for rs3773643 in TGFBR2, which has been implicated in aortic aneurysm and Loeys-Dietz syndrome $[18,19]$. Disruption of the aortic wall would be expected to affect arterial stiffness. 
Table 2: Results of GEE and FBAT Additive Genetic Effects: Association, Linkage, and Heritability of Blood Pressure and Arterial Stiffness Phenotypes

\begin{tabular}{|c|c|c|c|c|c|c|c|}
\hline \multicolumn{8}{|c|}{ 2a. Results of GEE Additive Genetic Effects Models } \\
\hline Phenotype & Exam & SNP & Chr. & Position & GEE $P$ value & FBAT $P$ value & Gene \\
\hline \multicolumn{8}{|c|}{ Diastolic Blood Pressure } \\
\hline DBP & 7 & rs|963982 & 8 & $73,269,470$ & $3.31 \times 10^{-6}$ & 0.002 & \\
\hline DBP & I & rs935334 & 14 & $75,683,431$ & $3.32 \times 10^{-6}$ & 0.002 & \\
\hline DBP & 7 & rs4370013 & 3 & $2,629,691$ & $3.73 \times 10^{-6}$ & 0.032 & CNTN4 \\
\hline DBP & 7 & rs10491334 & 5 & $110,800,303$ & $4.47 \times 10^{-6}$ & 0.133 & CAMK 4 \\
\hline DBP & I & rs2121070 & 14 & $75,720,517$ & $4.88 \times 10^{-6}$ & 0.02 & Cl4orflI8 \\
\hline DBP & 1 & rs2509458 & 6 & $88,709,299$ & $6.94 \times 10^{-6}$ & 0.001 & \\
\hline DBP & 7 & rs6950982 & 7 & $100,360,038$ & $1.22 \times 10^{-5}$ & 0.036 & TRIM56, SERPINEI, APISI \\
\hline DBP & 7 & rs10510911 & 3 & $63,678,681$ & $1.65 \times 10^{-5}$ & 0.021 & \\
\hline DBP & I & rs 1816088 & 5 & $39,897,583$ & $1.73 \times 10^{-5}$ & 0.012 & \\
\hline DBP & 7 & rs1519592 & 6 & $140,585,329$ & $1.89 \times 10^{-5}$ & $2.83 \times 10^{-4}$ & \\
\hline
\end{tabular}

\section{Systolic Blood Pressure}

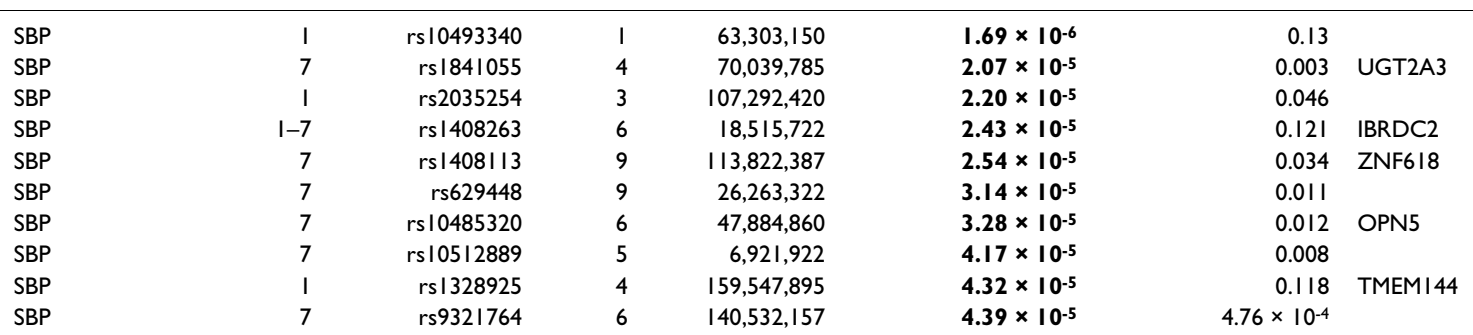

\begin{tabular}{|c|c|c|c|c|c|c|c|}
\hline \multicolumn{8}{|c|}{ Tonometry Phenotypes } \\
\hline RW & 7 & rs6063312 & 20 & $46,776,466$ & $2.09 \times 10^{-6}$ & 0.063 & PREXI \\
\hline CB-PWV & 7 & rs770189 & 5 & $88,124,195$ & $2.53 \times 10^{-6}$ & 0.005 & MEF2C \\
\hline CB-PWV & 7 & rs $105 \mid 4688$ & 3 & $34,937,673$ & $5.66 \times 10^{-6}$ & 0.027 & \\
\hline CB-PWV & 7 & rs7042864 & 9 & $107,951,862$ & $6.13 \times 10^{-6}$ & 0.077 & \\
\hline MAP & 7 & rs 1322512 & 6 & $153,040,067$ & $7.76 \times 10^{-6}$ & 0.038 & SYNEI \\
\hline FW & 7 & rs348384 & 19 & $6,503,386$ & $1.16 \times 10^{-5}$ & 0.058 & TUBB4, TNFSF9, TNFSF7 \\
\hline RW & 7 & rs 10507514 & 13 & $42,|32,8| 4$ & $1.28 \times 10^{-5}$ & 0.066 & TNFSFII \\
\hline FW & 7 & rs3793427 & 8 & $17,188,201$ & $1.43 \times 10^{-5}$ & 0.059 & VPS37A \\
\hline RW & 7 & rs 10506928 & 12 & $85,003,844$ & $1.62 \times 10^{-5}$ & 0.021 & \\
\hline FW & 7 & rs407570I & 2 & $116,146,020$ & $1.63 \times 10^{-5}$ & 0.025 & \\
\hline RW & 7 & rs II 784583 & 8 & $103,154,213$ & $3.83 \times 10^{-5}$ & 0.036 & \\
\hline RW & 7 & rs105I3957 & 18 & $65,039,417$ & $4.15 \times 10^{-5}$ & 0.019 & \\
\hline CF-PWV & 7 & rs 10506440 & 12 & $60,993,853$ & $4.18 \times 10^{-5}$ & 0.064 & USPI5 \\
\hline RW & 7 & rsII97850 & 13 & $34,828,744$ & $4.57 \times 10^{-5}$ & 0.042 & \\
\hline
\end{tabular}

2b. Results of FBAT Additive Genetic Effects Models

\begin{tabular}{|c|c|c|c|c|c|c|c|}
\hline Phenotype & Exam & SNP & Chr. & Position & GEE $P$ value & FBAT P Value & Gene \\
\hline DBP & I & rs1590919 & 13 & $104,000,000$ & 0.079 & $1.42 \times 10^{-6}$ & \\
\hline DBP & $1-7$ & rs636864 & 6 & $150,000,000$ & $4.49 \times 10^{-4}$ & $1.55 \times 10^{-6}$ & \\
\hline DBP & I & rs726698 & 2 & $35,366,992$ & 0.02 & $1.15 \times 10^{-5}$ & \\
\hline DBP & 7 & rs|338657 & 6 & $103,000,000$ & 0.001 & $2.57 \times 10^{-5}$ & \\
\hline DBP & $1-7$ & rs 10506595 & 12 & $69,191,621$ & 0.133 & $3.40 \times 10^{-5}$ & PTPRB \\
\hline DBP & 7 & rs931II7I & 3 & $37,97 \mid, 48 I$ & 0.025 & $4.03 \times 10^{-5}$ & CTDSPL \\
\hline DBP & I & rs 10520569 & 15 & $82,520,393$ & 0.577 & $4.24 \times 10^{-5}$ & ADAMTSL3 \\
\hline DBP & 7 & rs45I40I6 & 8 & $120,000,000$ & $3.70 \times 10^{-5}$ & $4.52 \times 10^{-5}$ & SAMDI 2 \\
\hline DBP & 7 & rs2322509 & 8 & $27,052,291$ & 0.172 & $4.91 \times 10^{-5}$ & \\
\hline DBP & $1-7$ & rs10504389 & 8 & $66,7|8,74|$ & 0.1 & $5.53 \times 10^{-5}$ & ARMCI, MTFRI \\
\hline SBP & I & rs 1588260 & 5 & $121,000,000$ & 0.001 & $3.43 \times 10^{-6}$ & \\
\hline SBP & I & rs726698 & 2 & $35,366,992$ & 0.023 & $2.70 \times 10^{-5}$ & \\
\hline SBP & 7 & rs 963328 & 1 & $209,000,000$ & 0.036 & $3.01 \times 10^{-5}$ & \\
\hline
\end{tabular}


Table 2: Results of GEE and FBAT Additive Genetic Effects: Association, Linkage, and Heritability of Blood Pressure and Arterial Stiffness Phenotypes (Continued)

\begin{tabular}{|c|c|c|c|c|c|c|c|}
\hline SBP & 7 & rs729053 & 18 & $50,960,679$ & 0.008 & $3.41 \times 10^{-5}$ & \\
\hline SBP & 7 & rs|434939 & 8 & $69,666,816$ & 0.004 & $4.97 \times 10^{-5}$ & \\
\hline SBP & $1-7$ & rs 10498500 & 14 & $62,030,261$ & 0.005 & $6.25 \times 10^{-5}$ & \\
\hline SBP & I & rs385324I & 5 & $166,000,000$ & 0.003 & $6.25 \times 10^{-5}$ & \\
\hline SBP & $1-7$ & rs1590919 & 13 & $104,000,000$ & 0.14 & $6.66 \times 10^{-5}$ & \\
\hline SBP & 1 & rs6763833 & 3 & $65,953,132$ & 0.374 & $8.18 \times 10^{-5}$ & MAGII \\
\hline SBP & 7 & rs6940II0 & 6 & $10,377,050$ & 0.145 & $8.42 \times 10^{-5}$ & \\
\hline FW & 7 & rsI539377 & 9 & $81,441,976$ & $5.48 \times 10^{-5}$ & $5.26 \times 10^{-6}$ & TLEI \\
\hline RW & 7 & rs792833 & 3 & $101,000,000$ & 0.123 & $6.01 \times 10^{-6}$ & COL8AI \\
\hline MAP & 7 & rs10495191 & I & $219,000,000$ & 0.007 & $1.46 \times 10^{-5}$ & TAFIA \\
\hline CB-PWV & 7 & rs10494786 & I & $196,000,000$ & 0.079 & $1.56 \times 10^{-5}$ & \\
\hline CB-PWV & 7 & rs2160595 & 18 & $61,742,129$ & 0.001 & $2.38 \times 10^{-5}$ & $\mathrm{CDH} 7$ \\
\hline FW & 7 & rs28899 & 5 & $82,798,839$ & 0.001 & $2.99 \times 10^{-5}$ & VCAN \\
\hline CF-PWV & 7 & rs |34972I & 4 & $86,693,958$ & 0.105 & $3.34 \times 10^{-5}$ & ARHGAP24 \\
\hline CB-PWV & 7 & rs300I450 & 9 & $93,164,925$ & 0.61 & $3.91 \times 10^{-5}$ & WNK2 \\
\hline CB-PWV & 7 & rs|389608 & 14 & $46,027,527$ & 0.111 & $4.08 \times 10^{-5}$ & \\
\hline RW & 7 & rs10499221 & 6 & $|4|, 000,000$ & 0.003 & $5.92 \times 10^{-5}$ & \\
\hline
\end{tabular}

2c. Linkage Results

\begin{tabular}{|c|c|c|c|c|c|c|}
\hline Phenotype & Exam & LOD & Chr. & Position & Lower bound* & Upper bound \\
\hline DBP & $1-7$ & 2.03 & 17 & $12,245,760$ & $9,173,838$ & $16,450,642$ \\
\hline SBP & $1-7$ & 3 & 15 & $100,152,332$ & $97,636,843$ & $100,152,332$ \\
\hline SBP & 7 & 2.55 & 15 & $79,161,506$ & $75,509,164$ & $85,958,968$ \\
\hline SBP & 7 & 2.39 & 3 & $129,657,137$ & $105,768,506$ & $14 \mid, 888,352$ \\
\hline SBP & $1-7$ & 2.18 & 5 & $41,710,612$ & $36,665,015$ & $67,696,396$ \\
\hline SBP & $1-7$ & 2.07 & 3 & $107,844,505$ & $99,203,989$ & $144,119,612$ \\
\hline SBP & 7 & 2.06 & 12 & $101,785,625$ & $94,922,502$ & $107,253,596$ \\
\hline RW & 7 & 5.02 & 8 & $19,102,897$ & $17,257,073$ & $21,506,898$ \\
\hline RW & 7 & 3.35 & 9 & $10,499,434$ & $6,759,229$ & $10,671,522$ \\
\hline RW & 7 & 3.17 & 4 & $\mid 69,091,021$ & $162,723,480$ & $170,955,956$ \\
\hline CF-PWV & 7 & 3.04 & 2 & $74,021,676$ & $49,795,460$ & $103,043,940$ \\
\hline CF-PWV & 7 & 2.68 & 18 & $40,229,747$ & $38,788,852$ & $43,206,229$ \\
\hline FW & 7 & 2.47 & 3 & $60,298,724$ & $24,621,158$ & $62,757,508$ \\
\hline RW & 7 & 2.47 & 15 & $100,152,332$ & $94,749,239$ & $100,152,332$ \\
\hline CF-PWV & 7 & 2.43 & 15 & $99,551,603$ & $92,469,518$ & $100,152,332$ \\
\hline RW & 7 & 2.29 & I & $12,153,078$ & $4,266,833$ & $17,528,974$ \\
\hline CF-PWV & 7 & 2.17 & 4 & II,998,283 & $7,901,357$ & $25,777,055$ \\
\hline
\end{tabular}

2d. Heritability of Blood Pressure and Arterial Stiffness Phenotypes

\begin{tabular}{lrrr}
\hline Phenotype & Exam & Heritability & s.e. \\
& & & \\
\hline DBP & 1 & 0.3 & 0.04 \\
DBP & 7 & 0.35 & 0.06 \\
DBP & $1-7$ & 0.55 & 0.05 \\
& & & \\
\hline SBP & 1 & 0.28 & 0.04 \\
SBP & 7 & 0.45 & 0.06 \\
SBP & $1-7$ & 0.57 & 0.04 \\
& & & \\
\hline CB-PWV & 7 & 0.02 & 0.09 \\
CF-PWV & 7 & 0.43 & 0.1 \\
FW & 7 & 0.22 & 0.09 \\
MAP & 7 & 0.32 & 0.1 \\
RW & 7 & 0.66 & 0.1
\end{tabular}

Association results based on minor allele frequency $>=0.1$, HWE $p$ value $>=0.001$, call rate $>=0.8$

$\mathrm{CB}-\mathrm{PWV}=$ carotid-brachial pulse wave velocity; CF-PWV = carotid-femoral pulse wave velocity; $\mathrm{DBP}=$ diastolic blood pressure; FW = forward wave amplitude; $\mathrm{MAP}=$ mean arterial pressure; RW = reflected wave amplitude; SBP = systolic blood pressure

* Lower and upper bounds for LOD-I.5 interval. 
Table 3: Results of GEE General Genetic Effects Model for Long-term Average Blood Pressure Phenotypes and Arterial Stiffness

\begin{tabular}{|c|c|c|c|c|c|}
\hline Phenotype & SNP & Chr. & Position & P value* & Gene \\
\hline \multicolumn{6}{|c|}{ Diastolic Blood Pressure (long-term average) } \\
\hline DBP & rs7591163 & 2 & $228,423,620$ & $2.90 \times 10^{-7}$ & CCL20, WDR69 \\
\hline DBP & rs1901167 & 5 & $40,996,921$ & $6.40 \times 10^{-5}$ & $\mathrm{C7}$ \\
\hline DBP & rs6829806 & 4 & $85,916,019$ & $8.10 \times 10^{-5}$ & CDSI \\
\hline DBP & rs6796000 & 3 & $189,874,2 \mid 3$ & $1.10 \times 10^{-4}$ & LPP \\
\hline DBP & rs3096277 & 16 & $82,321,705$ & $1.40 \times 10^{-4}$ & $\mathrm{CDHI} 3$ \\
\hline DBP & rs969049 & 4 & $99,346,035$ & $1.40 \times 10^{-4}$ & \\
\hline DBP & rs10503497 & 8 & $14,326,753$ & $1.40 \times 10^{-4}$ & SGCZ \\
\hline DBP & rs2262138 & 19 & $16,213,403$ & $2.10 \times 10^{-4}$ & FAM32A, APIMI \\
\hline DBP & rsl0509333 & 10 & $72,737,658$ & $3.70 \times 10^{-4}$ & UNC5B, SLC29A3 \\
\hline DBP & rs933296 & 12 & $109,837,230$ & $4.10 \times 10^{-4}$ & MYL2 \\
\hline
\end{tabular}

Systolic Blood Pressure (long-term average)

\begin{tabular}{|c|c|c|c|c|c|}
\hline SBP & rs3096277 & 16 & $82,321,705$ & $9.90 \times 10^{-8}$ & $\mathrm{CDHI} 3$ \\
\hline SBP & rs1721359 & 2 & $228,460,118$ & $1.00 \times 10^{-5}$ & CCL20, WDR69 \\
\hline SBP & rs225942 & 14 & $29,595,139$ & $5.30 \times 10^{-5}$ & PRKDI \\
\hline SBP & rs298988 & 4 & $119,867,850$ & $7.80 \times 10^{-5}$ & SEC24D \\
\hline SBP & rs105I4096 & 5 & $76,700,940$ & $1.10 \times 10^{-4}$ & PDE8B \\
\hline SBP & rs $105 \mid 2245$ & 9 & $95,771,366$ & $1.40 \times 10^{-4}$ & \\
\hline SBP & rs294593 & 5 & $163,000,000$ & $1.80 \times 10^{-4}$ & МАТ2B \\
\hline SBP & rs6085660 & 20 & $6,639,069$ & $1.90 \times 10^{-4}$ & BMP2 \\
\hline SBP & rs6796000 & 3 & $190,000,000$ & $2.20 \times 10^{-4}$ & LPP \\
\hline SBP & rs575I2I & 12 & $117,000,000$ & $2.20 \times 10^{-4}$ & TAOK 3 \\
\hline \multicolumn{6}{|c|}{ Tonometry } \\
\hline MAP & rs3773643 & 3 & $30,685,247$ & $1.99 \times 10^{-7}$ & TGFBR2 \\
\hline FW & rs3793427 & 8 & $17,188,20 \mid$ & $1.96 \times 10^{-6}$ & VPS37A \\
\hline RW & rs6492654 & 13 & $92,688,671$ & $2.28 \times 10^{-6}$ & GPC6 \\
\hline CF-PWV & rs 1367248 & 2 & $124,734,834$ & $2.88 \times 10^{-6}$ & CNTNAP5 \\
\hline CF-PWV & rs 10521232 & 17 & $13,480,529$ & $3.88 \times 10^{-6}$ & HS3ST3AI \\
\hline FW & rs3766680 & I & $173,563,0070$ & $4.15 \times 10^{-6}$ & TNR \\
\hline RW & rs1371924 & 3 & $144,732,760$ & $4.44 \times 10^{-6}$ & SLC9A9 \\
\hline RW & rs 10488172 & 7 & $132,985,7 \mid 6$ & $8.49 \times 10^{-6}$ & EXOC4 \\
\hline FW & rs 10507534 & 13 & $44,724,220$ & $1.05 \times 10^{-5}$ & GTF2F2 \\
\hline FW & rs7|9856 & 6 & $47,702,681$ & $1.21 \times 10^{-5}$ & CD2AP \\
\hline
\end{tabular}

*P values from 2 degree of freedom test

CB-PWV = carotid-brachial pulse wave velocity; CF-PWV = carotid-femoral pulse wave velocity; $\mathrm{DBP}=$ diastolic blood pressure; FW = forward wave amplitude; $\mathrm{MAP}=$ mean arterial pressure; $\mathrm{RW}=$ reflected wave amplitude; $\mathrm{SBP}=$ systolic blood pressure

Minor allele frequency $>=0.20$, HWE $P$ value $>=0.05$, call rate $>=0.80$

Due to high correlations of SBP and DBP (within examination $r=0.77$; long-term $r=0.82$ ), joint analyses of SBP and DBP added little to what was identified in individual phenotype analyses. In contrast, joint analyses of the five tonometry phenotypes, which are less highly correlated, identified LOXL2, SYNE1, and MEF2C as attractive candidates. LOXL2 is a member of the lysyl oxidase family of enzymes that initiate cross-linking of collagens and elastin, and alter arterial elasticity [20]. Collagen and elastin cross-links are critical to tensile strength of the extracellular matrix. Mice null for lysyl oxidase $(L O X)$ die perinatally from aortic aneurysm [21]. MEF2C is involved in cardiac morphogenesis and extracellular matrix remode- ling [22]. SYNE1 is involved in aortic vascular smooth muscle differentiation [23]. To our knowledge, genetic variation in these genes has not previously been shown to be associated with alterations in arterial properties in humans. Whether our results provide nominal evidence of such association or merely chance findings remains to be determined.

Since none of the primary associations attained genomewide significance, this investigation should be viewed as hypothesis generating. Association analyses for SNPs in six renin-angiotensin-aldosterone pathway genes showed weak evidence of association. Negative results for these 
Table 4: Top Results for Geometric Means of SBP and DBP Considered Jointly (at examinations I, 7 and in the long term), and arterial stiffness phenotypes considered jointly.

\begin{tabular}{|c|c|c|c|c|c|}
\hline SNP & Exam & Chr. & Position & $P$ value & Gene \\
\hline \multicolumn{6}{|c|}{ DBP and SBP } \\
\hline rs 10493340 & I & I & $63,303,150$ & $1.49 \times 10^{-5}$ & \\
\hline rs9321764 & 7 & 6 & $140,532,157$ & $2.89 \times 10^{-5}$ & \\
\hline rs 10491334 & 7 & 5 & $110,800,303$ & $3.74 \times 10^{-5}$ & CAMK 4 \\
\hline rs2121070 & 1 & 14 & $75,720,517$ & $3.96 \times 10^{-5}$ & Cl4orflI8 \\
\hline rsI328925 & I & 4 & $159,547,895$ & $4.22 \times 10^{-5}$ & TMEMI44 \\
\hline rs10510079 & I & 10 & $|22,473,10|$ & $7.27 \times 10^{-5}$ & \\
\hline rs7562854 & 7 & 2 & $12,149,816$ & $7.52 \times 10^{-5}$ & \\
\hline rs I84I055 & 7 & 4 & $70,039,785$ & $7.63 \times 10^{-5}$ & UGT2A3 \\
\hline rs 10485320 & 7 & 6 & $47,884,860$ & $7.75 \times 10^{-5}$ & OPN5 \\
\hline rs9298203 & 7 & 8 & $73,270,276$ & $8.28 \times 10^{-5}$ & \\
\hline
\end{tabular}

Arterial stiffness

\begin{tabular}{|c|c|c|c|c|c|}
\hline rs $105 \mid 8082$ & 7 & 4 & $72,282,885$ & 0.002 & DCK \\
\hline $\mathrm{rs} \mid 322512$ & 7 & 6 & $153,040,067$ & 0.005 & SYNEI \\
\hline rs 10511389 & 7 & 3 & $120,557,547$ & 0.007 & CDGAP \\
\hline rs883524 & 7 & 8 & $23,250,536$ & 0.008 & LOXL2 \\
\hline rs965674 & 7 & 5 & $82,518,340$ & 0.008 & $\mathrm{XRCC4}$ \\
\hline rs 10502173 & 7 & 11 & II2,708,233 & 0.009 & TTCI2 \\
\hline rs|4685I2 & 7 & 17 & $64,731,363$ & 0.010 & ABCAIO \\
\hline rs407570I & 7 & 2 & $116,146,020$ & 0.011 & \\
\hline rs 10496604 & 7 & 2 & $|23,50|, 987$ & 0.011 & \\
\hline rs770189 & 7 & 5 & $88,124,195$ & 0.011 & MEF2C \\
\hline
\end{tabular}

Based on Additive genetic effects model using GEE and minor allele frequency of 0.1 , call rate $>=0.80$ and $\mathrm{HWE} p$ value $>=0.00 \mathrm{I}$

candidate genes may be due in part to incomplete linkage disequilibrium coverage of these genes by the SNPs in this genome-wide scan. It is likely that the vast majority of low $\mathrm{p}$ values from association analyses are due to chance. Replication studies in other populations, using a genomewide approach or selective genotyping is needed to establish if any of our results are indicative of true positive associations.

We provide results of genome-wide association testing for blood pressure and arterial stiffness phenotypes obtained in a carefully described community-based sample of adults who were recruited without regard to disease status. Additional studies are needed to validate these results. Finding genetic variants associated with hypertension or altered arterial properties may aid in the identification of high risk individuals and in the development of new targeted therapies for hypertension. Our report is one of the earlier genome-wide association studies of blood pressure. Several additional studies, some with larger sample size and others with more dense genome-wide coverage of common variation will follow. In that regard, a $550 \mathrm{k}$ SNP genome-wide association study in approximately 9400 Framingham Heart Study participants across three generations is underway and results from that study will help in the interpretation of the findings we report in this manuscript.

\section{Abbreviations}

DBP = diastolic blood pressure; FBAT = family based association test; GEE = generalized estimating equation; LOD $=\log$ of the odds; SBP = systolic blood pressure; SNP = single nucleotide polymorphism.

\section{Competing interests}

GFM is owner of Cardiovascular Engineering, Inc, a company that designs and manufactures devices that measure vascular stiffness. All other authors declare that they have no competing interests.

\section{Authors' contributions}

EJB secured funding for tonometry measurements, assisted in planning the analyses, and critically revised the manuscript. CNC contributed to design, analysis, and critical review of the manuscript. SJH generated the phenotype data, participated in the analysis and interpretation of results. MGL assisted to secure funding for tonometry measurements, generated phenotype data, assisted in planning analyses, and critically revised the manuscript. DL conceived of the FHS tonometry project and assisted in securing funding, planned the analyses, interpreted the 
Table 5: Results for Pre-Specified Candidate Genes

\begin{tabular}{|c|c|c|c|c|c|}
\hline Candidate gene & Total number of SNPs* & SNPs with $p$ value $<0.05$ & Phenotype & GEE $p$ value & FBAT $p$ value \\
\hline \multicolumn{6}{|c|}{ Diastolic blood pressure } \\
\hline ACE & 3 & 0 & & & \\
\hline AGT & 13 & rs24785I8 & & 0.021 & 0.186 \\
\hline AGTRI & 17 & 0 & & & \\
\hline CYPIIB2 & I & 0 & & & \\
\hline $\mathrm{NR} 3 \mathrm{C} 2$ & 26 & rs6845733 & & 0.008 & 0.399 \\
\hline REN & 9 & 0 & & & \\
\hline \multicolumn{6}{|c|}{ Systolic blood pressure } \\
\hline $\mathrm{ACE}$ & 3 & 0 & & & \\
\hline AGT & 13 & rs2478518 & & 0.003 & 0.275 \\
\hline AGTRI & 17 & 0 & & & \\
\hline CYPIIB2 & 1 & 0 & & & \\
\hline \multirow[t]{2}{*}{$\mathrm{NR} 3 \mathrm{C} 2$} & 26 & rs6845733 & & 0.010 & 0.323 \\
\hline & & rs3916013 & & 0.024 & 0.598 \\
\hline REN & 9 & 0 & & & \\
\hline
\end{tabular}

\begin{tabular}{|c|c|c|c|c|c|}
\hline \multicolumn{6}{|c|}{ Arterial stiffness } \\
\hline ACE & 3 & 0 & & & \\
\hline \multirow[t]{4}{*}{ AGT } & 13 & rs731824 & MAP & 0.022 & 0.397 \\
\hline & & rs2478518 & $\mathrm{FW}$ & 0.024 & 0.688 \\
\hline & & rs24785I6 & FW & 0.037 & 0.217 \\
\hline & & rs24785I6 & RW & 0.046 & 0.663 \\
\hline \multirow[t]{2}{*}{ AGTRI } & 17 & rs1059502 & MAP & 0.025 & 0.023 \\
\hline & & rs427832 & FW & 0.046 & 0.963 \\
\hline CYPIIB2 & 1 & rs27I7594 & CF-PWV & 0.003 & 0.308 \\
\hline \multirow[t]{8}{*}{ NR3C2 } & 26 & rs3910046 & CF-PWV & 0.009 & 0.383 \\
\hline & & rs9307847 & CB-PWV & 0.011 & 0.741 \\
\hline & & rs3910046 & CB-PWV & 0.014 & 0.409 \\
\hline & & rs10519959 & CB-PWV & 0.018 & 0.175 \\
\hline & & rs3846317 & RW & 0.021 & 0.649 \\
\hline & & rs4835I36 & CB-PWV & 0.027 & 0.268 \\
\hline & & rs3846318 & RW & 0.042 & 0.293 \\
\hline & & rs10519958 & RW & 0.049 & 0.529 \\
\hline \multirow[t]{2}{*}{ REN } & 9 & rs 16776 & $\mathrm{FW}$ & 0.012 & 0.115 \\
\hline & & rs3911890 & FW & 0.022 & 0.207 \\
\hline
\end{tabular}

*Includes all SNPs within $200 \mathrm{~kb}$ of start to $200 \mathrm{~kb}$ beyond end of gene, with genotype call rate >= 0.8; minor allele frequency >= 0.I; HWE p >= 0.001

CB-PWV = carotid-brachial pulse wave velocity; CF-PWV = carotid-femoral pulse wave velocity; $\mathrm{DBP}=$ diastolic blood pressure; FW = forward wave amplitude; $\mathrm{MAP}=$ mean arterial pressure; $\mathrm{RW}=$ reflected wave amplitude; $\mathrm{SBP}=$ systolic blood pressure

results, and drafted the manuscript. GFM conceived of the FHS tonometry project and assisted in securing funding, planned the analyses, and critically revised the manuscript. RSV provided critical input in conceiving the project, securing the funding, planning the analyses and critically revising the manuscript. TJW contributed to design, analysis, and critical review of the manuscript.

\section{Acknowledgements}

We thank the Framingham Study participants and acknowledge support from NOI-HC 25195. Arterial tonometry was supported by the Donald W. Reynolds Foundation and NIH ROI-HL70I00 and ROI-HL60040 and K24-
HL04334. A portion of the research was conducted using the Boston University Linux Cluster for Genetic Analysis (LinGA) funded by the NIH NCRR (National Center for Research Resources) Shared Instrumentation grant (ISIORRI63736-0IAI).

We also wish to acknowledge the contributions of Dr. Christopher J. O'Donnell to this project.

This article has been published as part of BMC Medical Genetics Volume 8 Supplement I, 2007: The Framingham Heart Study 100,000 single nucleotide polymorphisms resource. The full contents of the supplement are available online at http://www.biomedcentral.com/I47I-2350/8? issue=SI. 


\section{References}

I. Fields LE, Burt VL, Cutler JA, Hughes J, Roccella EJ, Sorlie P: The burden of adult hypertension in the United States 1999 to 2000: a rising tide. Hypertension 2004, 44:398-404.

2. Lewington S, Clarke R, Qizilbash N, Peto R, Collins R: Age-specific relevance of usual blood pressure to vascular mortality: a meta-analysis of individual data for one million adults in 61 prospective studies. Lancet 2002, 360:1903-1913.

3. Sutton-Tyrrell K, Najjar SS, Boudreau RM, Venkitachalam L, Kupelian V, Simonsick EM, Havlik R, Lakatta EG, Spurgeon H, Kritchevsky S, et al.: Elevated aortic pulse wave velocity, a marker of arterial stiffness, predicts cardiovascular events in well-functioning older adults. Circulation 2005, I I I:3384-3390.

4. Willum-Hansen T, Staessen JA, Torp-Pedersen C, Rasmussen S, Thijs $\mathrm{L}$, Ibsen $\mathrm{H}$, Jeppesen J: Prognostic value of aortic pulse wave velocity as index of arterial stiffness in the general population. Circulation 2006, I I 3:664-670.

5. Leoncini G, Ratto E, Viazzi F, Vaccaro V, Parodi A, Falqui V, Conti N, Tomolillo C, Deferrari G, Pontremoli R: Increased ambulatory arterial stiffness index is associated with target organ damage in primary hypertension. Hypertension 2006, 48(3):397-403.

6. Levy D, DeStefano AL, Larson MG, O'Donnell CJ, Lifton RP, Gavras H, Cupples LA, Myers RH: Evidence for a Blood Pressure Gene on Chromosome I7: Genome Scan Results for longitudinal blood pressure phenotypes in subjects from the Framingham Heart Study. Hypertension 2000, 36:477-483.

7. Mitchell GF, DeStefano AL, Larson MG, Benjamin EJ, Chen MH, Vasan RS, Vita JA, Levy D: Heritability and a genome-wide linkage scan for arterial stiffness, wave reflection, and mean arterial pressure: the Framingham Heart Study. Circulation 2005, I I 2:194-199.

8. Lifton RL: Genetic dissection of human blood pressure variation: common pathways from rare phenotypes. Harvey Lect 2004, 100:71-101.

9. Koivukoski L, Fisher SA, Kanninen T, Lewis CM, von Wowern F, Hunt S, Kardia SL, Levy D, Perola M, Rankinen T, Rao DC, Rice T, Thiel BA, Melander O: Meta-analysis of genome-wide scans for hypertension and blood pressure in Caucasians shows evidence of susceptibility regions on chromosomes 2 and 3 . Hum Mol Genet I3( I 9):2325-32. 2004 Oct I;

10. Marteau JB, Zaiou M, Siest G, Visvikis-Siest S: Genetic determinants of blood pressure regulation. J Hypertens 2005, 23(I 2):2 I 27-43.

I I. Klein RJ, Zeiss C, Chew EY, Tsai JY, Sackler RS, Haynes C, Henning AK, SanGiovanni JP, Mane SM, Mayne ST, Bracken MB, Ferris FL, Ott J, Barnstable $\mathrm{C}$, Hoh J: Complement factor $\mathbf{H}$ polymorphism in age-related macular degeneration. Science 2005, 308:362-4.

12. Dawber TR, Meadors GF, Moore FEJ: Epidemiological approaches to heart disease: the Framingham Study. Am J Public Health 195I, 41:279-286. [Medline] [Order article via Infotrieve]

13. Kannel WB, Feinbleib M, McNamara PM, Garrison RJ, Castelli WP: An investigation of coronary heart disease in families: the Framingham Offspring Study. Am J Epidemiol 1979, I I 0:28 I-290. [Abstract/Free FullText]

14. Mitchell GF, Parise H, Benjamin EJ, Larson MG, Keyes MJ, Vita JA, Vasan RS, Levy D: Changes in arterial stiffness and wave reflection with advancing age in healthy men and women: the Framingham Heart Study. Hypertension 2004, 43(6): I239-45.

15. Cupples LA, Arruda H, Benjamin EJ, D'Agostino RB Sr, Demissie S, DeStefano AL, Dupuis J, Falls K, Fox CS, Gottlieb D, Govindaraju DR, Guo CY, Heard-Costa N, Hwang SJ, Katherisan S, Kiel D, Laramie JM, Larson MG, Levy D, Liu CY, Lunetta KL, Mailman M, Manning AK, Meigs JB, Murabito JM, Newton-Cheh C, O'Connor GT, O'Donnell C), Pandey MA, Seshadri S, Vasan RS, Wang ZY, Wilk JB, Wolf PA, Yang Q, Atwood LD: The Framingham Heart Study I 00K SNP genome-wide association study resource: Overview of 17 phenotype working group reports. BMC Med Genet 2007, 8(Suppl I):SI.

16. Abecasis GR, Cardon LR, Cookson WO: A general test of association for quantitative traits in nuclear families. Am J Hum Genet 2000, 66:279-292.

17. Adiguzel E, Hou G, Mulholland D, Hopfer U, Fukai N, Olsen B, Bendeck $M$ : Migration and growth are attenuated in vascular smooth muscle cells with type VIII collagen-null alleles. Arterioscler Thromb Vasc Biol 2006, 26:56-6I.
18. Boileau C, Jondeau G, Babron MC, Coulon M, Alexandre JA, Sakai L, Melki J, Delorme G, Dubourg O, Bonaiti-Pellie C, Bourdarias JP, Junien C: Autosomal dominant Marfan-like connective-tissue disorder with aortic dilation and skeletal anomalies not linked to the fibrillin gene. Am J Hum Genet 1993, 53:46-54.

19. Loeys BL, Schwarze U, Holm T, Callewaert BL, Thomas GH, Pannu H, De Backer JF, Oswald GL, Symoens S, Manouvrier S, Roberts AE, Faravelli F, Greco MA, Pyeritz RE, Milewicz DM, Coucke PJ, Cameron DE, Braverman AC, Byers PH, De Paepe AM, Dietz HC: Aneurysm syndromes caused by mutations in the TGF-beta receptor. N Engl J Med 2006, 24;355(8):788-798.

20. Maki JM, Sormunen R, Lippo S, Kaarteenaho-Wiik R, Soininen R, Myllyharju J: Lysyl oxidase is essential for normal development and function of the respiratory system and for the integrity of elastic and collagen fibers in various tissues. Am J Pathol 2005, 167:927-36.

21. Maki JM, Rasanen J, Tikkanen H, Sormunen R, Makikallio K, Kivirikko $\mathrm{KI}$, Soininen R: Inactivation of the lysyl oxidase gene Lox leads to aortic aneurysms, cardiovascular dysfunction, and perinatal death in mice. Circulation 2002, 106:2503-2509.

22. Verzi MP, McCulley DJ, De Val S, Dodou E, Black BL: The right ventricle, outflow tract, and ventricular septum comprise a restricted expression domain within the secondary/anterior heart field. Dev Biol 2005, 287: | 34-45.

23. Zhang Q, Skepper JN, Yang F, Davies JD, Hegyi L, Roberts RG, Weissberg PL, Ellis JA, Shanahan CM: Nesprins: a novel family of spectrin-repeat-containing proteins that localize to the nuclear membrane in multiple tissues. J Cell Sci 200 I, I I 4:4485-98.
Publish with Bio Med Central and every scientist can read your work free of charge

"BioMed Central will be the most significant development for disseminating the results of biomedical research in our lifetime. "

Sir Paul Nurse, Cancer Research UK

Your research papers will be:

- available free of charge to the entire biomedical community

- peer reviewed and published immediately upon acceptance

- cited in PubMed and archived on PubMed Central

- yours - you keep the copyright

Submit your manuscript here:

http://www.biomedcentral.com/info/publishing_adv.asp
BiolMedcentral 